\title{
Stanniocalcin 1 promotes cell proliferation via cyclin E1/cyclin-dependent kinase 2 in human prostate carcinoma
}

\author{
YAO BAI $^{1}$, YICHEN XIAO $^{3}$, YUANQING DAI $^{2}$, XIONG CHEN $^{1}$, DONGJIE LI $^{1}$, XINJI TAN $^{1}$ and XIAOBO ZHANG ${ }^{1}$ \\ ${ }^{1}$ International Medical Center and ${ }^{2}$ Department of Geriatric Medicine, Xiang Ya Hospital, Central South University, \\ Changsha, Hunan 410008; ${ }^{3}$ The Medical College of Nanchang University, Nanchang, Jiangxi 330006, P.R. China
}

Received July 7, 2016; Accepted August 23, 2016

DOI: $10.3892 /$ or.2017.5501

\begin{abstract}
Stanniocalcin 1 (STC1) is a glycoprotein hormone that is involved in calcium/phosphate homeostasis. Increasing evidence suggests that STC1 is involved in carcinogenesis; however, few studies have defined the mechanisms and functional roles of STC1 activity in prostate carcinogenesis. In the present study, MTT, flow cytometry and colony formation assays, and small interfering RNA (siRNA) and overexpression in multiple cell lines were used to investigate the function of STC1 in prostate carcinoma in vivo and in vivo. Knockdown of endogenous STC1 using a siRNA decreased the proliferation of DU145 and LNCaP2 cells. These results were consistent with the changes in the protein levels of cyclin E1 and cyclin-dependent kinase 2. By contrast, increased expression of STC1 in RWPE-1 cells led to increased cell proliferation, suggesting that STC1 promotes prostate carcinoma cell proliferation. In summary, the present study investigated the impact of STC1 on the proliferation and growth of prostate cancer in an effort to evaluate STC1 as a predictive biomarker and as a potential target for therapy.
\end{abstract}

\section{Introduction}

Prostate carcinoma is one of the most prevalent malignant tumors in males. In 2012, 241,740 cases of prostate carcinoma were diagnosed in the US, and this was the most common type of newly diagnosed tumor among males, accounting for $29 \%$ of new diagnoses. It also accounted for $\sim 28,170$ mortalities, ranking as the second most common cause of cancer-related mortality in males (1). It is estimated that 220,800 new cases of prostate carcinoma were diagnosed in 2015, and 27,540

Correspondence to: Professor Xiaobo Zhang, International Medical Center, Xiang Ya Hospital, Central South University, 78 Xiangya Road, Changsha, Hunan 410008, P.R. China

E-mail: xiaobozxb@hotmail.com

Key words: stanniocalcin 1, prostate carcinoma, proliferation, cyclin E1/cyclin-dependent kinase 2 mortalities were attributed to prostate carcinoma (2). Despite numerous studies, the pathogenesis of prostate carcinoma has not been fully elucidated (3-5). Novel diagnostic markers and improved treatment strategies for prostate carcinoma must be further explored.

Orr et al (6) demonstrated that the stanniocalcin 1 (STC1) expression pattern was varied in prostate carcinomas. The results indicated that STC1 may be crucial during prostate carcinoma progression and development. Numerous experiments need to be conducted to further explore the role of STC1 in prostate carcinogenesis and its potential as a novel cancer biomarker

STC1 is a peptide hormone that was initially identified in teleost fish and is widely expressed in mammalian tissues $(7,8)$. Its function and mechanism are complex. STC1 is involved in the regulation of calcium and phosphorus, inflammatory reactions and vascular sclerosis $(9,10)$. Law and Wong (11) identified a hypoxia-inducible factor-1 $\alpha$ (HIF-1 $\alpha)$ binding motif in the promoter region of the STC1 gene, indicating that STC1 expression may be responsive to hypoxia in human tumors. The present study demonstrates that STC1 is overexpressed in the prostate carcinoma cell lines DU145 and $\mathrm{LNCaP} 2$. A series of experiments were performed to study the function of STC1 in prostate carcinoma, and to improve the understanding of prostate cancer pathogenesis.

\section{Materials and methods}

Cell culture. LNCaP2 and DU145 prostate carcinoma and normal prostate RWPE-1 cells were cultured in Gibco RPMI-1640 medium, supplemented with $10 \%$ fetal bovine serum (FBS) (both from Gibco, Thermo Fisher Scientific, Inc., Waltham, MA, USA). The cells were incubated at $37^{\circ} \mathrm{C}$ in an atmosphere of $5 \% \mathrm{CO}_{2}$.

Reverse transcription-polymerase chain reaction (RT-PCR). mRNA was isolated from two prostate carcinoma and one normal prostatecelllines, andreverse transcribed andamplified using a One-Step RT-PCR System (Fermentas, Vilnius, Lithuania). The following primer sequences were used for PCR: GAPDH antisense, 5'-CCTGCTTCACCACCTTCTTG-3' and sense, 5'-AATCCCATCACCATCTTCCA-3'; STC1 
sense, 5'-TTCTGGTGCTGGTGATCAGTG-3' and antisense, 5'-TTTGGGCACAGTGGTCTGTCT-3'. Samples were initially heated to $95^{\circ} \mathrm{C}$ for $1 \mathrm{~min}$, then subjected to 30 cycles (GAPDH, 28 cycles) of $95^{\circ} \mathrm{C}$ for $30 \mathrm{sec}, 56^{\circ} \mathrm{C}$ for $30 \mathrm{sec}$ and $72^{\circ} \mathrm{C}$ for $90 \mathrm{sec}$; a final 10 -min extension step at $72^{\circ} \mathrm{C}$ was also included. All reaction products were purified on $1 \%$ agarose gels containing ethidium bromide. The relative expression levels of mRNA were analyzed by a Phosphor-Imager.

Western blot analysis. The sample cells were washed with cold phosphate-buffered saline (PBS), and then lysed in Laemmli buffer [62.5 mM Tris-HCl (pH 6.8), 2\% SDS, $10 \%$ glycerol, $50 \mathrm{mM}$ dithiothreitol and $0.01 \%$ bromphenol blue] for $5 \mathrm{~min}$ at $98^{\circ} \mathrm{C}$. Cell lysate samples were separated by SDS-PAGE, and the proteins were electrophoretically transferred to polyvinylidene difluoride membranes. The blots were subsequently blocked for $1 \mathrm{~h}$ with non-fat milk and probed with the specific primary antibodies followed by a secondary detection step. The immunoreactive proteins were revealed by an enhanced chemiluminescence kit. The following antibodies were used in the western blotting: rabbit anti-STC1 (Santa Cruz Biotechnology, Inc., Santa Cruz, CA, USA), rabbit anti-cyclin D1 (Cell Signaling Technology, Inc., Danvers, MA, USA), rabbit anti-cyclin E1 (Abcam, Cambridge, MA, USA), rabbit anti-cyclin-dependent kinase 4 (CDK4), and rabbit anti-CDK2 (both from Santa Cruz Biotechnology, Inc.).

Vector construction and cell transfection. To knock down STC1 expression, a pRNAT-U6.1/Neo vector encoding a small interfering RNA (siRNA) directed against the target gene, STC1, in prostate cells was utilized (si-STC1). The target sequence for STC1 was, 5'-TTAGTCCAGGAAGCAATAGTA-3'. An empty pRNAT-U6.1/Neo vector was used as a negative control (NC). For transfection, prostate carcinoma cells were cultured to $70 \%$ confluency, transfected with a recombinant plasmid, and harvested after $48 \mathrm{~h}$ for further experiments.

Methyl thiazolyl tetrazolium (MTT) and colony formation assays. For the MTT assay, the cells were seeded in 96-well plates at a density of $10^{3}$ cells/well $(\mathrm{n}=6)$ and cultured for 12 , 24,48 or $72 \mathrm{~h}$. Subsequently, the cells were incubated with $10 \mu 1$ MTT (50 $\mu \mathrm{g} /$ well; Sigma-Aldrich, St. Louis, MO, USA) for $4 \mathrm{~h}$. The generated formazan was assessed at $490 \mathrm{~nm}$ to detect the cell viability.

Additionally, a colony formation assay was conducted as previously described (12).

Flow cytometric analysis. Cells were cultured in RPMI-1640 medium containing $1 \%$ FBS for the first $24 \mathrm{~h}$ and $10 \%$ FBS for the subsequent $24 \mathrm{~h}(\mathrm{n}=3)$. The cells were then harvested and resuspended in fixation fluid at a density of $10^{6}$ cells $/ \mathrm{ml}$. Propidium iodide (PI) solution $(1,500 \mu \mathrm{l})$ was then added, and the cell cycle was analyzed using a FACSCalibur flow cytometer (BD Biosciences, San Diego, CA, USA).

Tumor formation in nude mice. To evaluate tumor growth in vivo, cells transfected with the si-STC1 or NC vectors (DU145/si-STC1, DU145/NC, LNCaP2/si-STC1 and LNCaP2/NC; $5 \times 10^{6}$ cells/mouse) were subcutaneously injected into 4-week-old BALB/c nude mice ( $\mathrm{n}=3$ /group; Shanghai Laboratory Animal Center, Shanghai, China). The experimental pairs (DU145/si-STC1 and DU145/NC; and $\mathrm{LNCaP} 2 / \mathrm{si}-\mathrm{STC} 1$ and $\mathrm{LNCaP} 2 / \mathrm{NC}$ ) were established in different mice. The development and growth of solid tumors were monitored by measuring tumor size using a Vernier caliper in a blinded manner every 5 days for a 40 -day period, and the following formula was used to calculate tumor volume: Tumor volume $=$ width $^{2} \mathrm{x}$ length $\mathrm{x} 0.5$. All nude mice were sacrificed and individual tumor weights were gauged at the end of the experiment. The animal experimental protocols were approved by the Ethics Committee of Xiangya Hospital of Central South University.

Statistical analysis. All experiments were repeated and data are expressed as the mean \pm standard deviations. Differences among $>2$ groups were assessed by ANOVA, and differences between 2 groups were analyzed using a Student's t-test. Analyses were performed with GraphPad Prism software version 5.0 (GraphPad Software, Inc., San Diego, CA, USA). Statistical significance was indicated by $\mathrm{P}<0.05$.

\section{Results}

$m R N A$ and protein expression of STCl in prostate carcinoma and normal prostate cell lines. The mRNA and protein expression levels of STC1 were assessed by RT-PCR and western blotting in the normal prostate (RWPE-1) and prostate carcinoma (DU145 and LNCaP2) cell lines. The results revealed that STC1 mRNA and protein levels were markedly higher in the DU145 and LNCaP2 cells compared with the RWPE-1 cells (Fig. 1A and B).

Effect of STC1 knockdown on prostate cancer cell proliferation. To examine the biological function of STC1, STC1-knockdown DU145 and LNCaP2 cells were established. As shown in Fig. 2A and B, cells stably transfected with si-STC1 had markedly decreased levels of STC1 mRNA and protein compared with the control group cells (DU145/NC and $\mathrm{LNCaP} 2 / \mathrm{NC}$ ).

The effect of STC1 knockdown on the proliferation of prostate cancer cells (DU145 and LNCaP2) was determined using MTT analysis. During a 6-day period, the proliferation results suggested that DU145/si-STC1 and LNCaP2/si-STC1 cells proliferated more slowly compared with DU145/NC and LNCaP2/NC cells (Fig. 2C and D). Additionally, colony formation assays were used to investigate the effect of decreased STC1 expression in DU145 and LNCaP2 cells (Fig. 2E-H), also indicating that downregulation of STC1 expression inhibited cell proliferation in vivo.

Flow cytometric analysis was also used to assess cell proliferation. The results demonstrated that transfection with si-STC1 led to increased G1 phase cell cycle arrest in DU145 and LNCaP2 cells (Fig. 3A-D). This result was in agreement with the previous analyses.

Overexpression of STC1 promotes RWPE-1 cell proliferation. Given the aforementioned results, we hypothesized that STC1 overexpression may promote RWPE-1 cell proliferation. To confirm this, cells were transfected with a plasmid encoding 
A

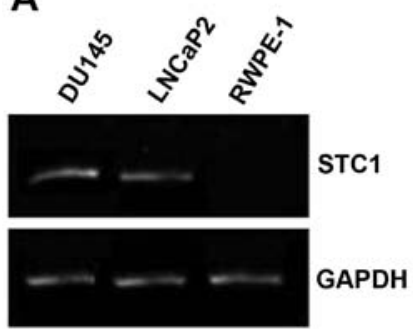

B

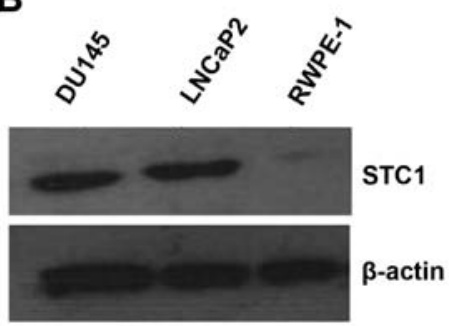

Figure 1. Expression of STC1 mRNA and protein in DU145 and LNCaP2 prostate carcinoma and RWPE-1 normal prostate cell lines. (A) STC1 and GAPDH mRNA expression levels were examined by reverse transcription-polymerase chain reaction. (B) STC1 and $\beta$-actin protein expression levels were examined by western blotting. STC1, stanniocalcin 1 .

A



C



E

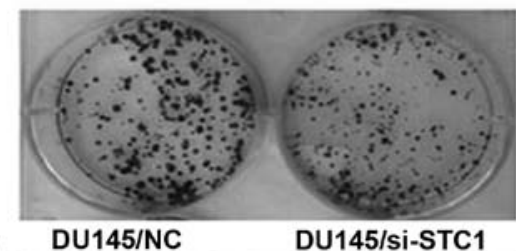

G

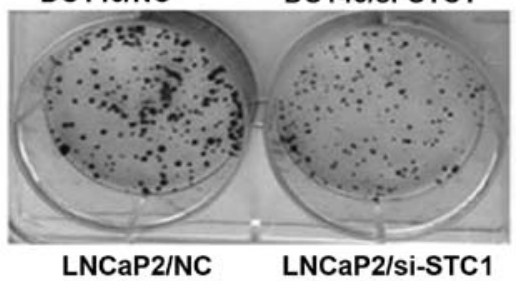

B
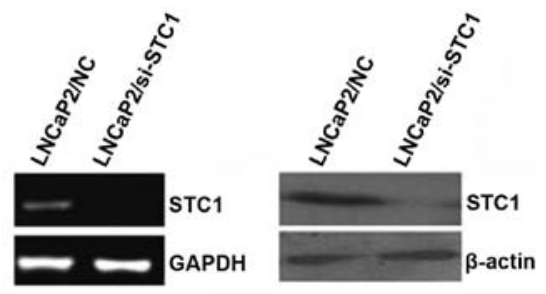

D

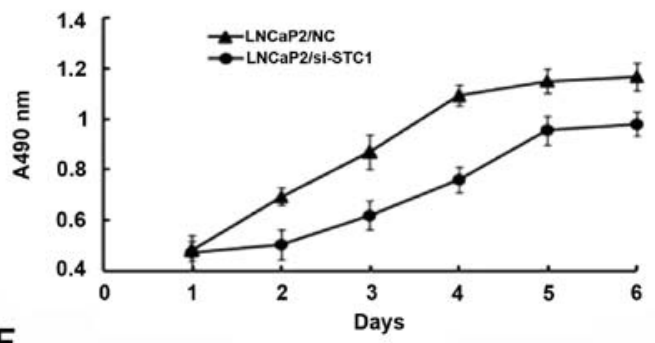

F

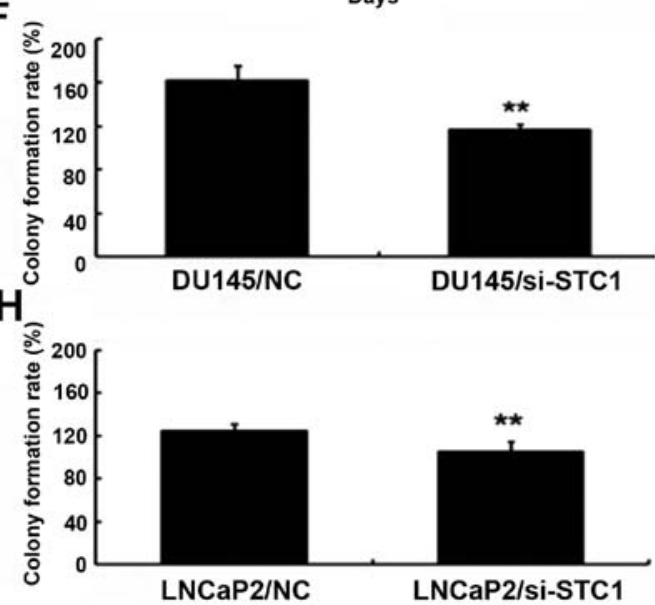

Figure 2. Knockdown of STC1 inhibits the proliferation of prostate cancer cells. The effect of STC1 knockdown in (A) DU145 and (B) LNCaP2 prostate cancer cell lines was assessed by reverse transcription-polymerase chain reaction (left panels) and western blotting (right panels). MTT assays demonstrated the effect of STC1 knockdown (si-STC1) on the proliferation of (C) DU145 and (D) LNCaP2 compared with their respective NC group cells. Colony formation analysis revealed the effects of si-STC1 and NC transfection on (E and F) DU145 cells $\left({ }^{* *} \mathrm{P}<0.05\right.$ vs. DU145/NC) and $(\mathrm{G}$ and $\mathrm{H}) \mathrm{LNCaP} 2$ cells $\left({ }^{* *} \mathrm{P}<0.01\right.$ vs. LNCaP2/NC). STC1, stanniocalcin 1; NC, negative control.

STC1 (RWPE-1-STC1), and these cells exhibited increased levels of STC1 mRNA and protein compared with the control group (RWPE-1-C; Fig. 4A). An MTT proliferation analysis indicated that RWPE-1-STC1 cells had a higher rate of proliferation compared with RWPE-1-C cells (Fig. 4B). Similarly, a colony formation assay revealed that STC1 overexpression promoted the growth of RWPE-1-STC1 cells compared with the control cells. These results indicated that upregulation of STC1 expression promoted cell proliferation in vivo (Fig. $4 \mathrm{C}$ and $\mathrm{D}$ ).

Furthermore, flow cytometric analysis demonstrated that in RWPE-1-STC1 cells a smaller proportion of cells were arrested in the G1 phase, while the percentage of cells in the $\mathrm{S}$ phase was increased compared with that in the RWPE-1-C cells (Fig. 4E and F). This result was also consistent with the aforementioned analyses. 

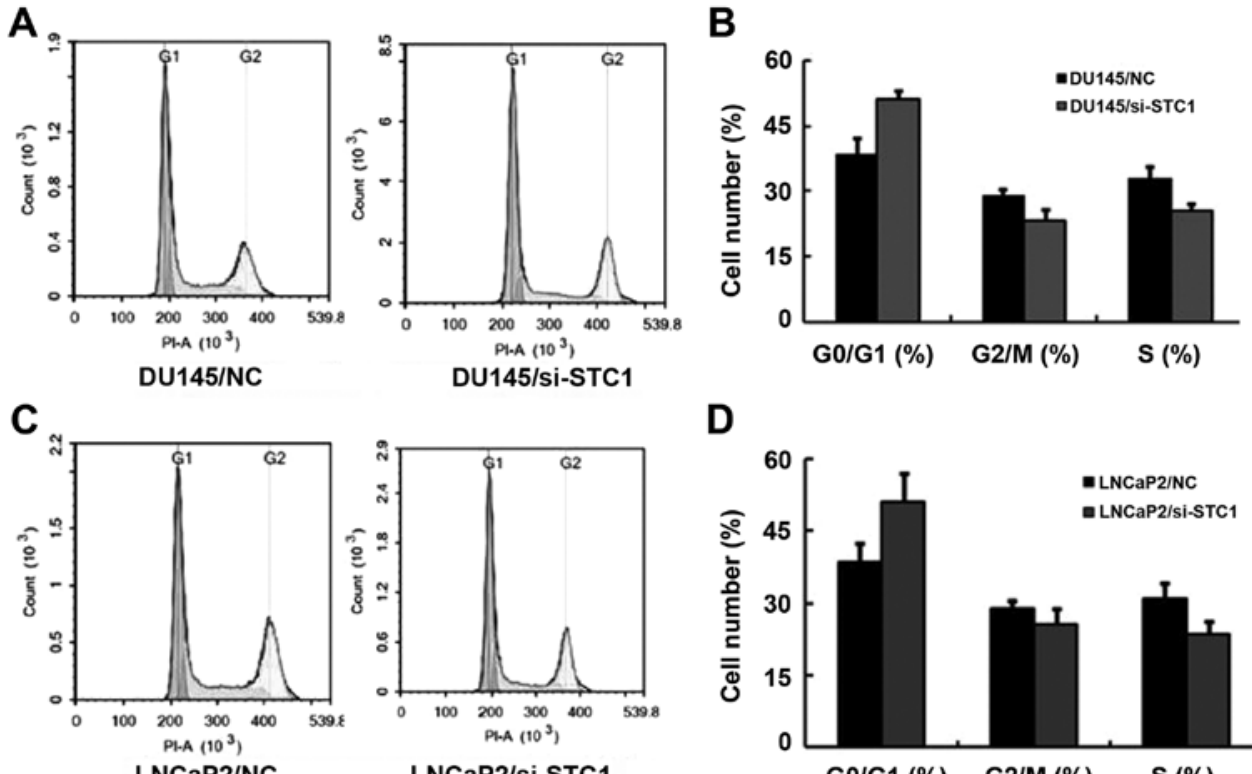

DU145/si-STC

D
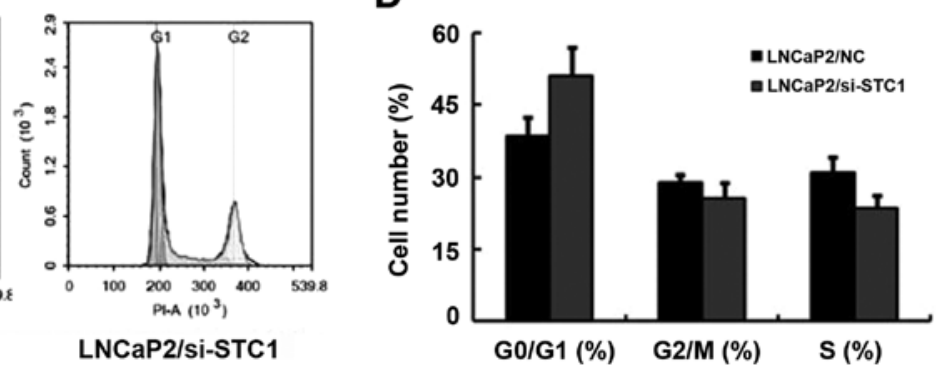

Figure 3. Flow cytometric analysis of cell cycle distribution in prostate cancer cells with or without STC1 knockdown. (A) Cell cycle distribution of DU145/NC and DU145/si-STC1 cells, and (B) the percentages of DU145/NC and DU145/si-STC1 cells in the G0/G1, G2/M and S phases. (C) Cell cycle distribution of $\mathrm{LNCaP} 2 / \mathrm{NC}$ and LNCaP2/si-STC1 cells and (D) the percentages of LNCaP2/NC and LNCaP2/si-STC1 cells in the G0/G1, G2/M and S phases. STC1, stanniocalcin 1; NC, negative control; si-STC1, STC1 knockdown.

A
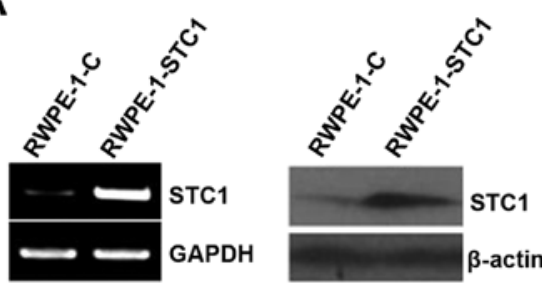

C

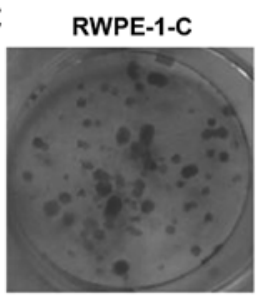

E

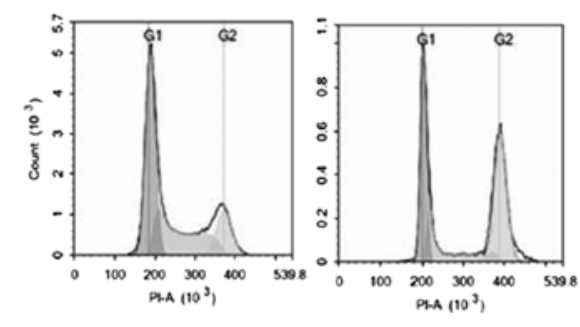

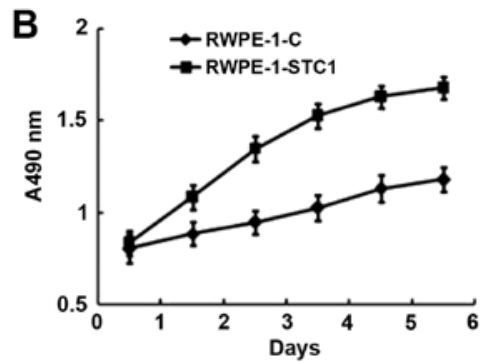

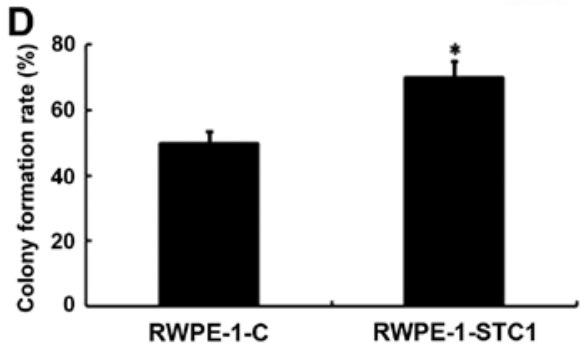

F

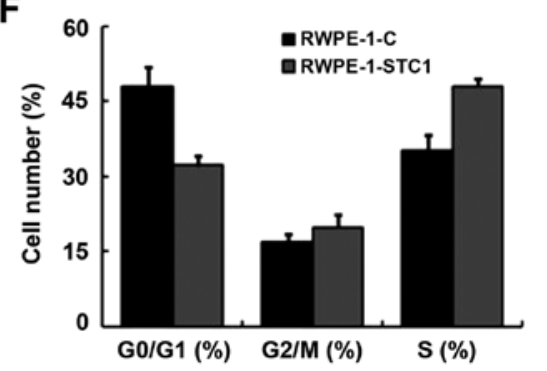

Figure 4. Overexpression of STC1 promotes cell proliferation in RWPE-1 normal prostate cells. (A) The overexpression of STC1 in transfected RWPE-1 cells was confirmed by reverse transcription-polymerase chain reaction (left panels) and western blotting (right panels). (B) An MTT assay demonstrated the effect of STC1 on the proliferation of RWPE-1-STC1 and control group cells. (C and D) Colony formation analysis was performed on RWPE-1-STC1 and RWPE-1-C cells ( ${ }^{*}<0.01$ vs. RWPE-1-C). (E) Cell cycle distributions of RWPE-1-STC1 and RWPE-1-C and (F) the percentages of RWPE-1-STC1 and RWPE-1-C cells in the G0/G1, G2/M and S phases. RWPE-1-C, control RWPE-1 cells; RWPE-1-STC1, RWPE-1 cells overexpressing STC1.

Tumor formation in nude mice. To further determine the effects of STC1 on tumor growth and development in vivo,
DU145/si-STC1 and LNCaP2/si-STC1 or DU145/NC and LNCaP2/NC cells were subcutaneously implanted into 
A

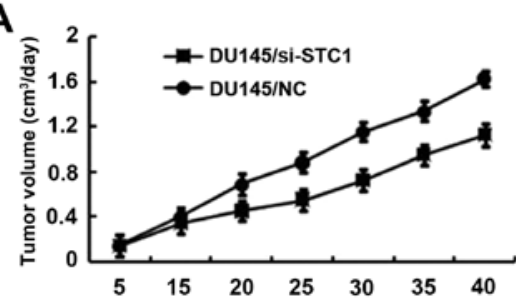

C

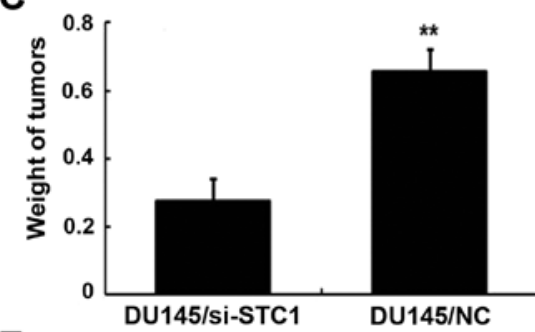

E

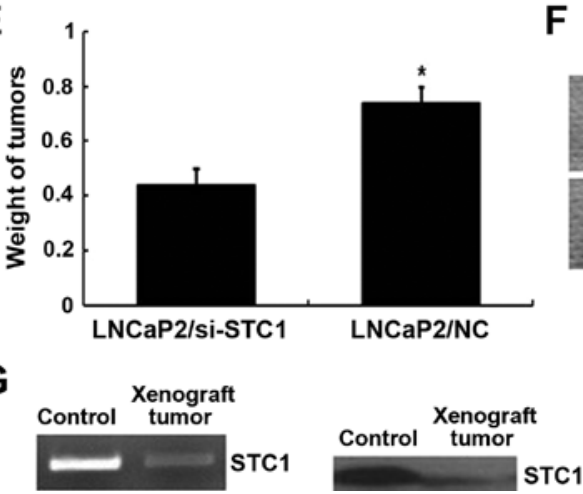

B

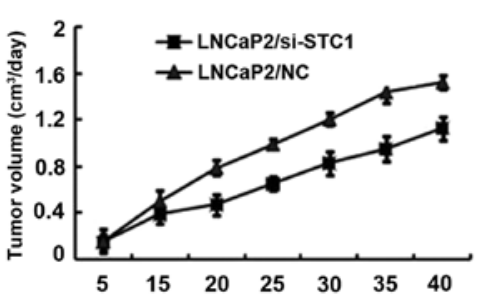

D

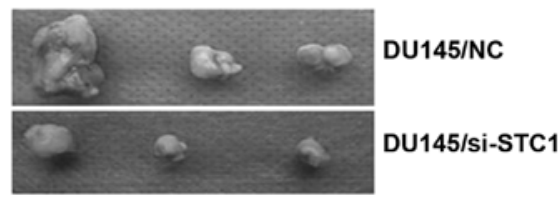

$\mathbf{F}$

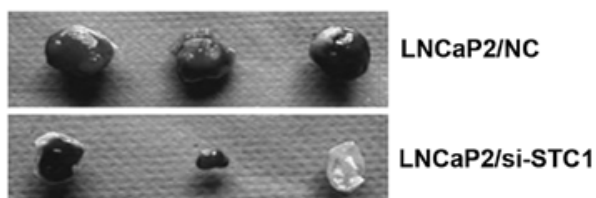

Figure 5. Tumor formation in nude mice. (A and B) The tumor volumes of nude mice were assessed every 5 days for a total of 40 days. " $\mathrm{P}<0.01 \mathrm{vs.} \mathrm{LNCaP2/si-STC1}$ ${ }^{* *} \mathrm{P}<0.01$ vs. DU145/si-STC1. (C-F) After 40 days, the weights of the tumors were recorded. (G) The expression levels of STC1 in the xenograft tumors generated from STC1-knockdown and control cells (without STC-1 knockdown) were verified by reverse transcription-polymerase chain reaction and western blot analyses. STC1, stanniocalcin 1; si-STC1, STC1 knockdown; NC, negative control.

4-week-old nude mice. After 40 days of growth, the nude mice were sacrificed and the tumor weight was assessed. As shown in Fig. 5A and B, STC1-knockdown tumors emerged later and grew more slowly compared with the control tumors. After 40 days, tumors developed from STC1-knockdown DU145 and LNCaP2 cells $(0.276 \pm 0.065$ and $0.441 \pm 0.057 \mathrm{~g}$, respectively) weighed less than the DU145 and LNCaP2 control group tumors $(0.658 \pm 0.098$ and $0.739 \pm 0.072 \mathrm{~g}$, respectively) (Fig. 5C-F). The STC1 mRNA and protein expression in tumor tissue removed from the nude mice was also monitored by RT-PCR and western blotting (Fig. 5G). These results suggested that STC1 promoted xenograft tumor development in vivo.

STC1 affects the expression of cell cycle-related proteins in prostate carcinoma cells, normal prostate cells and xenograft tumors. Previous studies revealed that cyclin D/CDK4 and cyclin E/CDK2 have vital roles in cell cycle progression and are often overexpressed in cancer cells (12). To confirm the association between STC1 expression and cell cycle-related proteins in prostate carcinoma and normal prostate cells and xenograft tumors, the expression levels of cyclin D1/CDK4 and cyclin E1/CDK2 were evaluated using western blotting. The results revealed that $\mathrm{STC} 1$ knockdown had no significant effect on cyclin D1/CDK4 protein levels (data not shown). However, the protein levels of cyclin E1 and CDK2 were decreased by the downregulation of endogenous STC1 in prostate carcinoma
A
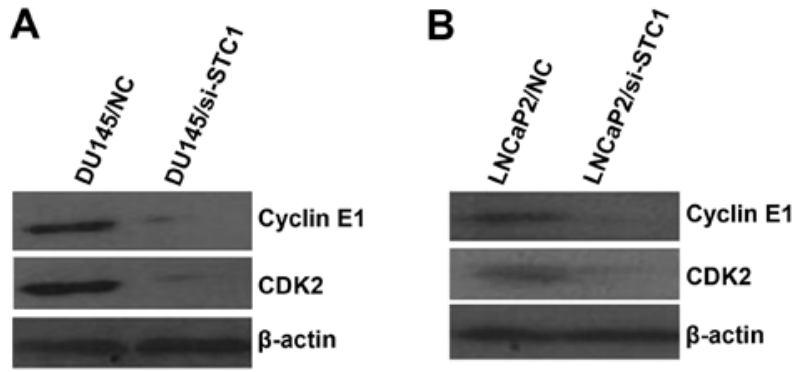

C
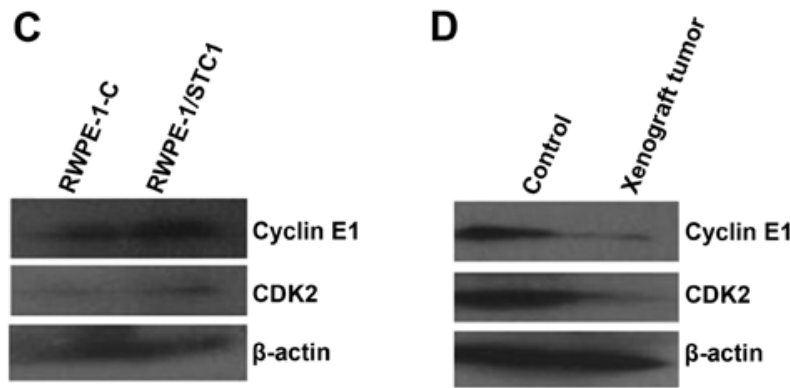

Figure 6. Expression levels of cyclin E1/CDK2 were verified by western blotting. (A and B) Cyclin E1 and CDK2 protein expression levels were detected in the prostate carcinoma cells with or without STC1 knockdown. Cyclin E1 and CDK2 protein expression levels were detected in (C) normal prostate cells with or without STC1 overexpression, and (D) xenograft tumors with or without STC1 overexpression. CDK2, cyclin-dependent kinase 2; STC1, stanniocalcin 1; NC, negative control; si-STC1, STC1 knockdown; RWPE-1-C, control RWPE-1 cells; RWPE-1/STC1, RWPE-1 cells overexpressing STC1. 
cell lines (Fig. 6A and B). Consistent results were also obtained in RWPE-1-STC1 cells and xenograft tumors by western blot analyses (Fig. 6C and D).

\section{Discussion}

Extensive evidence suggests that the STC1 participates in various types of carcinoma, including colorectal cancer (13), renal cell (14) and laryngeal squamous cell carcinoma (15), ovarian (16) and non-small cell lung cancer (17), and breast carcinoma (18). Previous research has also shown that STC1 is overexpressed in prostate carcinoma (6), suggesting that STC1 may play a significant role in this type of cancer. In the present study, STC1 was detected in a normal prostate cell line and two prostate carcinoma cell lines. The results illustrated that STC1 may regulate the growth and metastasis of prostate carcinoma, as its expression levels were markedly increased in the prostate carcinoma cell lines (DU145 and LNCaP2) compared with the normal prostate cell line. To ascertain how STC1 regulates prostate cell proliferation, STC1 was knocked down in prostate carcinoma cells and overexpressed in normal prostate cells. The results revealed that knockdown of STC1 induced a decrease in cell proliferation, while overexpression of STC1 in RWPE-1 cells promoted cell growth.

Recent studies (19) have demonstrated that STC1 participates in cancer progression and metastasis, which prompted our investigation into the role of STC1 in prostate cancer development and progression. Certain authors (20) have suggested that STC1 can regulate the calcium concentration in cells and activate a series of intracellular signals, which may result in tumor cell proliferation and invasion, and provide the necessary conditions for migration. In addition, STC1 can increase the phosphorus concentration in the cell. Therefore, the overexpression of STC1 in tumor cells may be associated with adaptation to a hypoxic environment (21).

In the present study, a flow cytometric analysis was performed to assess cell cycle distribution. Cell proliferation is controlled by cell cycle progression, which is regulated by numerous cell proliferation signaling pathways (22-24). In contrast to normal cells, the cell cycle is unregulated in cancer cells. Studies have demonstrated that the cell cycle is controlled via various cyclins and CDKs (12). Cyclins are essential for the regulation of the cell cycle and the activation of CDKs (25-27). In the present study, prostate carcinoma cells transfected with si-STC1 exhibited cell cycle arrest in the G1 phase, and decreased proliferative and tumorigenic abilities. Previous studies have indicated that cyclin E1/CDK2 is vital in various cancer-associated processes, including tumor formation, invasion and metastasis $(28,29)$. The results of the present study supported that the function of cyclin E1/CDK2 is associated with prostate carcinoma cell growth, as noted in multiple previous experiments (30). It is established that cyclin E1/CDK2 activation promotes cell proliferation and replication; however, the precise effects of cyclin E1/CDK2 require further study.

In conclusion, to the best of our knowledge, the present study is the first to suggest STC1 as a potential biomarker associated with the development and metastasis of prostate carcinoma. The results indicate a novel mechanistic role for STC1 in the regulation of prostate carcinoma cell proliferation via cyclin E1/CDK2. This novel biomarker may aid in clinical treatment and prediction of prognosis in prostate carcinoma. Further research is necessary to explore the regulatory mechanism of STC1.

\section{Acknowledgements}

The present study was supported by the Natural Science Foundation of Hunan Province (14JJ7004), and the Independent Innovation Foundation of Central South University (2016zzts516) (Changsha, China).

\section{References}

1. Siegel R, Naishadham D and Jemal A: Cancer statistics for Hispanics/Latinos, 2012. CA Cancer J Clin 62: 283-298, 2012.

2. Siegel RL, Fedewa SA, Miller KD, Goding-Sauer A, Pinheiro PS, Martinez-Tyson D and Jemal A: Cancer statistics for Hispanics/Latinos, 2015. CA Cancer J Clin 65: 457-480, 2015.

3. Hoyne G, Rudnicka C, Sang QX, Roycik M, Howarth S, Leedman P, Schlaich M, Candy P and Matthews V: Genetic and cellular studies highlight that A Disintegrin and Metalloproteinase 19 is a protective biomarker in human prostate cancer. BMC Cancer 16: 151, 2016.

4. Marzec J, Mao X, Li M, Wang M, Feng N, Gou X, Wang G, Sun Z, Xu J, Xu H, et al: A genetic study and meta-analysis of the genetic predisposition of prostate cancer in a Chinese population. Oncotarget 7: 21393-21403, 2016.

5. Zhou C, Dai X, Chen Y, Shen Y, Lei S, Xiao T, Bartfai T, Ding J and Wang MW: G protein-coupled receptor GPR160 is associated with apoptosis and cell cycle arrest of prostate cancer cells. Oncotarget 7: 12823-12839, 2016.

6. Orr B, Riddick AC, Stewart GD, Anderson RA, Franco OE, Hayward SW and Thomson AA: Identification of stromally expressed molecules in the prostate by tag-profiling of cancerassociated fibroblasts, normal fibroblasts and fetal prostate. Oncogene 31: 1130-1142, 2012

7. Ono M, Ohkouchi S, Kanehira M, Tode N, Kobayashi M,Ebina M, Nukiwa T, Irokawa T, Ogawa H, Akaike T, et al: Mesenchymal stem cells correct inappropriate epithelial-mesenchyme relation in pulmonary fibrosis using stanniocalcin-1. Mol Ther 23: 549-560, 2015.

8. Ohkouchi S, Ono M, Kobayashi M, Hirano T, Tojo Y, Hisata S, Ichinose M, Irokawa T, Ogawa $\mathrm{H}$ and Kurosawa $\mathrm{H}$ : Myriad functions of stanniocalcin-1 (STC1) cover multiple therapeutic targets in the complicated pathogenesis of idiopathic pulmonary fibrosis (IPF). Clin Med Insights Circ Respir Pulm Med 9 (Suppl 1): S91-S96, 2015.

9. Lee S, Naesens M, Li L and Sarwal M: Stanniocalcin supports the functional adaptation of adult-sized kidneys transplanted into the pediatric recipients. Transplantation 93: 1130-1135, 2012.

10. Tang SE, Wu CP, Wu SY, Peng CK, Perng WC, Kang BH, Chu SJ and Huang KL: Stanniocalcin-1 ameliorates lipopolysaccharide-induced pulmonary oxidative stress, inflammation, and apoptosis in mice. Free Radic Biol Med 71: 321-331, 2014.

11. Law AY and Wong CK: Stanniocalcin-2 is a HIF-1 target gene that promotes cell proliferation in hypoxia. Exp Cell Res 316: 466-476, 2010.

12. Li Y, Yang XH, Fang SJ, Qin CF, Sun RL, Liu ZY, Jiang BY, Wu $X$ and Li G: HOXA7 stimulates human hepatocellular carcinoma proliferation through cyclin E1/CDK2. Oncol Rep 33: 990-996, 2015.

13. Peña C,Céspedes MV,Lindh MB, Kiflemariam S, Mezheyeuski A, Edqvist PH, Hägglöf C, Birgisson H, Bojmar L, Jirström K, et al: STC1 expression by cancer-associated fibroblasts drives metastasis of colorectal cancer. Cancer Res 73: 1287-1297, 2013.

14. Ma X, Gu L, Li H, Gao Y, Li X, Shen D, Gong H, Li S, Niu S, Zhang Y, et al: Hypoxia-induced overexpression of stanniocalcin-1 is associated with the metastasis of early stage clear cell renal cell carcinoma. J Transl Med 13: 56, 2015.

15. Zhou H, Li YY, Zhang WQ, Lin D, Zhang WM and Dong WD: Expression of stanniocalcin-1 and stanniocalcin-2 in laryngeal squamous cell carcinoma and correlations with clinical and pathological parameters. PLoS One 9: e95466, 2014. 
16. Liu G, Yang G, Chang B, Mercado-Uribe I, Huang M, Zheng J, Bast RC, Lin SH and Liu J: Stanniocalcin 1 and ovarian tumorigenesis. J Natl Cancer Inst 102: 812-827, 2010.

17. Du YZ, Gu XH, Li L and Gao F: The diagnostic value of circulating stanniocalcin-1 mRNA in non-small cell lung cancer. J Surg Oncol 104: 836-840, 2011.

18. Chang AC, Doherty J, Huschtscha LI, Redvers R, Restall C, Reddel RR and Anderson RL: STC1 expression is associated with tumor growth and metastasis in breast cancer. Clin Exp Metastasis 32: 15-27, 2015.

19. Park WY, Hong BJ, Lee J, Choi C and Kim MY: H3K27 demethylase JMJD3 employs the NF- $\kappa$ B and BMP signaling pathways to modulate the tumor microenvironment and promote melanoma progression and metastasis. Cancer Res 76: 161-170, 2016.

20. Gu J, Law AY, Yeung BH and Wong CK: Activation of gill $\mathrm{Ca}^{2+}$ sensing receptor as a protective pathway to reduce $\mathrm{Ca}^{2+}$-induced cytotoxicity. J Mol Endocrinol 53: 155-164, 2014.

21. Shi X, Wang J and Qin Y: Recombinant adeno-associated virus-delivered hypoxia-inducible stanniocalcin-1 expression effectively inhibits hypoxia-induced cell apoptosis in cardiomyocytes. J Cardiovasc Pharmacol 64: 522-529, 2014.

22. Nagappan A, Lee HJ, Saralamma VV, Park HS, Hong GE, Yumnam S, Raha S, Charles SN, Shin SC, Kim EH, et al: Flavonoids isolated from Citrus platymamma induced G2/M cell cycle arrest and apoptosis in A549 human lung cancer cells. Oncol Lett 12: 1394-1402, 2016.

23. Huang Y, Zhao S, Zhang Y, Zhang C and Li X: Downregulation of coding transmembrane protein 35 gene inhibits cell proliferation, migration and cell cycle arrest in osteosarcoma cells. Exp Ther Med 12: 581-588, 2016.
24. Tsai TC, Huang HP, Chang KT, Wang CJ and Chang YC: Anthocyanins from roselle extract arrest cell cycle $\mathrm{G} 2 / \mathrm{M}$ phase transition via ATM/Chk pathway in p53-deficient leukemia HL-60 cells. Environ Toxicol: Jul 22, 2016 (Epub ahead of print). doi: $10.1002 /$ tox.22324.

25. Huang MY,Xuan F,LiuW andCuiHJ: MINA controls proliferation and tumorigenesis of glioblastoma by epigenetically regulating cyclins and CDKs via H3K9me3 demethylation. Oncogene: Jun 13, 2016 (Epub ahead of print). doi: 10.1038/onc.2016.208

26. Hydbring P, Malumbres M and Sicinski P: Non-canonical functions of cell cycle cyclins and cyclin-dependent kinases. Nat Rev Mol Cell Biol 17: 280-292, 2016.

27. de Azevedo WF: Opinion paper: Targeting multiple cyclin-dependent kinases (CDKs): A new strategy for molecular docking studies. Curr Drug Targets 17: 2, 2016.

28. Liu QX, Wang XF, Ikeo K, Hirose S, Gehring WJ and Gojobori T: Evolutionarily conserved transcription factor Apontic controls the G1/S progression by inducing cyclin $E$ during eye development. Proc Natl Acad Sci USA 111: 9497-9502, 2014.

29. Gladden AB and Diehl JA: Cell cycle progression without cyclin E/CDK2: Breaking down the walls of dogma. Cancer Cell 4: 160-162, 2003.

30. Rath SL and Senapati S: Why are the truncated cyclin Es more effective CDK2 activators than the full-length isoforms? Biochemistry 53: 4612-4624, 2014. 